\title{
Orígenes de la planeación regional en Colombia y sus retos ante el territorio del siglo XXI
}

\author{
Origens do planejamento regional na Colômbia e seus desafios para o \\ território do século XXI
}

Origins of regional planning in Colombia and its challenges for the territory of the $21^{\text {st }}$ century

César Augusto Velandia Silva [a] [D], Juan José Ospina-Tascón [b] [D]

[a] Universidad de Ibagué, Facultad de Humanidades, Artes y Ciencias Sociales, Ibagué, Tolima, Colombia.

[b] Universidad del Tolima, Facultad de Tecnologías, Ibagué, Tolima, Colombia.

Cómo citar: Silva, C. A. V., \& Ospina-Tascón, J. J. (2021). Orígenes de la planeación regional en Colombia y sus retos ante el territorio del siglo XXI. urbe. Revista Brasileira de Gestão Urbana, v.13, e20200419. DOI 10.1590/2175-

3369.013.e20200419

\section{Resumen}

El artículo pretende la puesta en valor de los orígenes del pensamiento geográfico regional en Colombia y explicar las dinámicas que implican los retos de la planeación regional del siglo XXI, materializadas actualmente en las Regiones Administrativas de Planificación (RAP). La investigación pretende contribuir al conocimiento y la interpretación de los retos que presenta la asociatividad aplicada desde la ciencia geográfica (humana y cultural), e indagar en los orígenes etnoculturales de las formas de ordenamiento regional y de las políticas que influyen espacialmente en el territorio colombiano. Este espíritu pervive en el proceso de concreción de las RAP, las que los autores atribuyen a Fals Borda en "La insurgencia de las provincias" (1988). Las cuales se debaten ante la necesidad de rescatar las bases naturales-culturales para la sostenibilidad del territorio y la innovación social. El proceso iniciado por Fals Borda culmina con la Ley 1962 de 2019, que establece las bases para la construcción de la Región Entidad Territorial (RET).

Palabras clave: Planeación Regional. Regiones Asociativas de Planificación. RAP Colombia. Geografía Cultural. Fals Borda.

\section{Resumo}

O presente artigo visa destacar as origens do pensamento geográfico regional na Colômbia e explicar as dinâmicas envolvidas nos desafios do planejamento regional no século XXI, atualmente incorporadas nas Regiões de Planejamento Administrativo (RAP). A pesquisa visa contribuir para o conhecimento e interpretação dos desafios da associatividade aplicada a partir da perspectiva da ciência geográfica (humana e cultural), e investigar as origens etno-culturais das formas de planejamento e políticas regionais que influenciam espacialmente o território colombiano. Este espírito continua vivo no processo de desenvolvimento dos RAPs, que os autores atribuem a Fals Borda em "La insurgencia de las provincias" (1988). Estes são debatidos diante da necessidade de resgatar as bases naturais-culturais para a sustentabilidade do território e a inovação social. $O$ 
processo iniciado por Fals Borda culmina com a Lei 1962 de 2019, que estabelece as bases para a construção da Região da Entidade Territorial (RET).

Palavras-chave: Planejamento Regional; Regiões de Planejamento Associativo; RAP Colômbia; Geografia Cultural; Fals Borda.

\section{Abstract}

The article is intended to highlight the origins of regional geographic thinking in Colombia and to explain the dynamics involved in the challenges of regional planning in the twenty-first century, currently materialized in the Planning Administrative Regions (RAP). The research aims to contribute to the knowledge and interpretation of the challenges presented by applied associativity from the perspective of geographic science (human and cultural) and to investigate the ethnocultural origins of the regional forms of organization and policies that spatially influence the Colombian territory. This spirit remains in the process of concretization of the RAPS, which the authors attribute to Fals Borda in "La insurgencia de las provincias" (1988). These are discussed given the need to rescue the natural-cultural bases for the sustainability of the territory and social innovation. The process initiated by Fals Borda culminates with Law 1962 of 2019, which establishes the basis for the construction of the Territorial Entity Region (RET).

Keywords: Regional Planning. Associative Planning Regions. RAP Colombia. Cultural Geography. Fals Borda.

\section{Introdução}

El artículo pretende explicar las dinámicas que implican los retos de la planeación regional en Colombia materializadas actualmente en la figura y forma legal de las Regiones Administrativas de Planificación (RAP), con origen en la geografía cultural de los años 70. La investigación pretende contribuir al conocimiento y la interpretación de los retos que presentan ante el siglo XXI, las figuras de asociatividad aplicadas a regiones; en atención a las demandas de las comunidades, los nuevos enfoques a la planificación territorial y el desarrollo regional.

Las RAP, "son la figura establecida en la Constitución de 1991, según la cual dos o más departamentos pueden constituirse [...] con el objeto de promover el desarrollo económico y social del respectivo territorio [...] pudiendo las RAP transformarse en (Regiones) entidades territoriales (RET) por decisión del Congreso, previo concepto de la COT (Comisión de Ordenamiento Territorial) y de un referendo de los ciudadanos de los departamentos involucrados" (Moncayo, 2004).

Lo anterior, se sustentó por la Ley Orgánica de Ordenamiento Territorial (LOOT) (Congreso de la República de Colombia, 2011), que en sus bases se fundamentan en Fornaguera \& Guhl (1969) y Fals Borda, (1988, 1996, 1998, 2000a, 2000b, 2003), quienes detonaron los aspectos de inclusión, equidad y justicia social muy innovadores en esa época. Lo anterior ha situado la reflexión sobre la organización y el funcionamiento espacial del sistema urbano regional en Colombia, así como sus relaciones históricas con el pensamiento regional (CEPAL, 2013).

Debe tenerse en cuenta, que este proceso histórico sucedió en un ámbito de cambio global-local del concepto de región. Según Sassen (2007), la transición a la economía global supuso el reposicionamiento de las ciudades y las regiones urbanas debido a los cambios en las escalas, los espacios y los contenidos de las actividades económicas, las cuales se concentraron con una mayor tendencia en mega regiones apoyadas en la expansión de flujos transfronterizos. En términos espaciales, estos procesos han tenido efectos en la organización de los sistemas urbanos y las relaciones entre la metrópoli, la periferia y la región, motivando los procesos de desconcentración y flujos migratorios, y nuevos escenarios relacionados con la aparición de usos y actividades dispersas que gravitan entre lo urbano y lo rural. En el marco de la discusión sobre los efectos de la ciudad-región (Boisier, 2006), bajo los procesos de metropolización, aglomeraciones con crecimiento inercial y grandes expresiones de poder manifestadas en desequilibrios y dominancias en la 
organización territorial (Alfonso, 2014) y "explosión urbana" (ONU-HÁBITAT, 2012). En la región de Latinoamérica, Colombia presenta un caso muy diferenciado, según IGAC (2011, p. 259):

El proceso urbano en Colombia ha presentado ciertas particularidades, si se compara con países similares en cuanto a características culturales y económicas. La principal singularidad es la dispersión relativa de la población urbana, por lo menos hasta mediados de la década de los setenta. A diferencia de la mayoría de los países de Suramérica y México, donde la urbanización se caracterizó por el crecimiento exagerado, respecto a los demás, de un solo centro urbano en un proceso conocido como primacía urbana, en el país se desarrolló una estructura urbana caracterizada por el surgimiento de cuatro ciudades principales: Bogotá, Medellín, Cali y Barranquilla, cada una con una región de influencia diferenciada, en un fenómeno llamado cuadricefalia urbana.

\section{Antecedentes}

La antropogeografía estudia al ser humano en cuanto a su distribución en la tierra en momentos históricos específicos, sus niveles de civilización y la relación del hombre con el entorno natural, además del desarrollo en cuanto aspectos económicos, políticos, sociales y culturales (Lindon \& Hiernaux, 2006; Luna García, 1999; Jackson, 1989; Garcia, 1985; Belil \& Clos, 1983). En la "geografía cultural” (Sauer, 1962), el paisaje es el componente central de investigación y de reconstrucción histórica del medio natural habitado por el hombre que lo modifica y constituye regiones culturales homogéneas definidas en base al uso de los recursos locales; además de aquellos elementos inmateriales simbólicos como las creencias, las lenguas y los dialectos; asimismo compromete el estudio de la ecología cultural histórica, donde centra su atención en la percepción y uso del paisaje que condiciona su cultura (Belil \& Clos, 1983; Jackson, 1989). Sumado al auge de una era de la tecnología y la información (Castells, 1995) ha llevado a interpretar el territorio como un todo de datos forzados entre lugares y sociedad (Santos, 2000).

El estudio de la región antropogeográfica en Colombia inicia con Ernesto Guhl Nimtz, considerado como el pionero de la geografía moderna colombiana (Universidad Nacional de Colombia - UN, 2015), quien manifestó que "la importancia y consecuencias del problema en sí sobre una región determinada se logra únicamente a través de la visión en conjunto y de la interdependencia de las interacciones de un número de factores basados en una metodología conceptual-universal de la geografía que analiza la influencia de los elementos naturales y sociales sobre el proceso de desarrollo o estancamiento social y económico en un conjunto espacial-regional" (Fals Borda, 1988, p. 149).

El proceso de la regionalización en Colombia, originalmente concebido a partir de las regiones naturales-culturales, respondió a modelos espaciales de la llamada Nueva Geografía Económica (De Mattos, 2000; Moncayo, 2004; Fujita \& Krugman, 2004; Banco Mundial, 2009; Valdivia \& Delgadillo, 2013), definidos por la transformación antrópica o la manera en que la sociedad capitalista se relacionó en condiciones espaciales heterogéneas u homogéneas de acuerdo con sus dinámicas propias.

Por ejemplo, las propuestas de Sánchez \& Núñez (2000) y Molina \& Moreno (2001), desarrollaron un modelo de jerarquización funcional y descentralización de los centros urbanos a partir de variables relacionadas con la disponibilidad de comunicaciones, infraestructura y servicios terciarios; identificaron los subsistemas urbanos inscritos en las regiones y subregiones; y propusieron acciones de política pública para el mejoramiento de la competitividad de los centros urbanos y superar los desequilibrios diagnosticados (Gaviria \& Aristizábal, 2020).

Lo anterior genera una reflexión sobre el estudio del control ciudadano del poder y la inclusión de la participación popular en las regiones. Trujillo (2007), sustenta que la descentralización como política y proceso de desarrollo articulado con los espacios regionales, construye autonomías desde la participación de diversos actores sociales, que tienen la oportunidad de integrar un "auténtico espacio democrático" (Trujillo, 2007, p. 265). Un escenario social que ha propiciado la formación de una nueva democracia local, cuyas gestiones más cívicas que políticas desenvueltas dentro de la microestructura veredal-municipal, poseen dinámicas integrativas muy complejas e incluso eficientes como organizaciones de la sociedad civil, 
representadas en el territorio, por ejemplo, por las Juntas de Acción Local. Esto contrasta con los problemas del panorama externo, tales como la transformación en los liderazgos, la crisis geopolítica y económica global, y en el contexto nacional: el posconflicto, la violencia de Estado, y la necesidad de las reformas estructurales, que confirman el replanteamiento del Estado-Nación.

\section{Los Epicentros Urbano-Regionales}

En Colombia, la conceptualización de la organización y la configuración del funcionamiento de la estructura urbano regional se remontan al estudio del epicentrismo regional de Fornaguera \& Guhl (1969), retomado por (Fals Borda 1988; 1991; Instituto Geográfico Agustín Codazzi, 1986; Sarmiento, 1998; Ibarra, 2009; Salazar, 2012; Gaviria \& Aristizábal, 2020; Rueda \& Ramírez, 2014; Moncayo, 2004). La propuesta de Fornaguera \& Guhl (1969) resulta del diagnóstico de:

La distancia entre el texto legal que ignora a las provincias y la conflictiva realidad ambiente que queda descrita, debido a la resistencia de aquellas a desaparecer [...] se dramatizaron las inconsistencias del sistema imperante de límites territoriales internos para fines del buen manejo de la cosa pública [...] problemas sociopolíticos tan evidentes no podían pasar desapercibidos [...] (Fornaguera \& Guhl) empezaron a documentar el fenómeno desde mediados de la década de 1960 [...] determinaron técnicamente las grandes divisiones que intuitivamente había propuesto Luis López de Mesa en 1934, sino que confirmaron la existencia de provincias o comarcas en el país, por supuesto delimitadas según el efecto de las pulsaciones de la vida colectiva desarrollada en los últimos decenios (Fals Borda, 1991, p. 54).

El estudio da cuenta del "modelo mecanicista" (Fals Borda, 2000, p. 46) sometido a la división política departamental. "Se analizaron dos tipos de regionalización posibles: una, basada en criterios físicos o físicobiológicos, y otra sustentada en criterios políticos-administrativos. La segunda, la consideraron como obsoleta, para efectos del análisis y descripción de los fenómenos humanos que por ese momento se producían en el territorio colombiano: creación de nuevos departamentos, tendencias a modificar legalmente, el régimen municipal y departamental, la creación de corporaciones regionales" (Rueda \& Ramírez, 2014, p. 47). "El epicentrismo urbano” consideró que la especialización funcional urbana crea un sistema de dependencias reciprocas con estructuras variadas y manifiestas en una red más o menos compleja, en la que el núcleo urbano principal es el epicentro en tanto juega un rol de centro económico, de servicios, de comunicación, de intercambio de información, de creación y difusión de innovaciones e ideas, para su población y área circundante (Gaviria \& Aristizábal, 2020; Sarmiento, 1998; De Mattos, 2000).

$\mathrm{Al}$ respecto Moncayo (2004), resalta un problema complejo: la intensificación de la expansión de un fenómeno territorial derivado de las áreas metropolitanas que tienen a desbordar los límites de sus hinterlands y asumir dimensiones de carácter regional, pues responden a un fenómeno de divergencia en contraposición de la convergencia de sus vecinos menos desarrollados o dotados de menor atractividad relativa, pero que dependen de ella para la interacción regional. De Mattos (2000), sostiene que la creciente difusión de los modelos de crecimiento endógeno, a partir de la interpretación del crecimiento económico desde las estrategias del modelo neoliberal debería asegurar el libre juego del mercado, de manera que este pudiese conducir hacia un mayor equilibrio interregional. Explica que la dinámica económica condiciona y acota el papel de las políticas que podrían aplicarse para promover el crecimiento y justifican la idea de gestión endógena como medio para activar el potencial de cada territorio (nacional o subnacional), de acuerdo por la sustitución de una tendencia de crecimiento impulsada bottom-up o "desde abajo". El modelo, en caso de ser adoptado por el Estado mediante políticas públicas, supone la activación de territorios menos desarrollados, y en su caso permitiría reducir la brecha de las desigualdades interregionales y generar una mayor convergencia.

De Mattos (2000), reflexiona sobre si la inducción de un proceso de acumulación desigual puede constituirse en un factor adverso para los territorios de menor desarrollo, en la medida que tal acumulación se enfoque hacia la divergencia. Por lo tanto, sugiere que el desarrollo endógeno debe darse en el 
fortalecimiento del rezago interno y del beneficio interno, no en función de inversión externa; en la medida de sus excepcionalidades y cualidades intrínsecas, y con mayor énfasis en el desarrollo de un capital cultural y social.

En 1970, el Departamento Nacional de Planeación (DNP), inició los estudios de "regionalización nodal", "cuyo objetivo era la configuración de la red urbana a partir de la delimitación de áreas y centros administrativos con capacidad de servir de canales para la difusión del desarrollo. Estas administrativas" (Moncayo, 2004, p. 170). Se definieron 12 regiones nodales: Amazonia, Caribe, Central, Eje Cafetero, Insular, Noroccidental, Nororiental, Orinoquia, Pacífico Sur, Piedemonte Amazónico, Piedemonte Llanero, y Sur de Bolívar, "las cuales corresponden al área de influencia que genera un centro urbano polarizante a su alrededor, donde muchas veces traspasa los límites político-administrativos departamentales. El nivel jerárquico de una ciudad es proporcional al alcance que tiene sobre la región que polariza" (Instituto Geográfico Agustín Codazzi, 2011, p. 233).

\section{La Región Etnocultural}

La "Región Etnocultural" se basa en la "provincia". Para Fals Borda (1991) la provincia es "el conjunto de municipios o territorios étnicos contiguos y vinculados por razones históricas, culturales, sociales, económicas o ecológicas, que libremente deciden organizarse como entidad político-administrativa, y que ocupan un espacio geográfico predominantemente rural. En el caso rural, las asociaciones de municipios quedarían asimiladas desde 1986, al esquema de la provincia con su propia estructura" (Fals Borda, 1991, p. 51). Se trata de "espacios intermedios entre los municipios y las regiones, especialmente en los ámbitos históricos y políticos" (Rueda \& Ramírez, 2014, p. 51).

La Constitución de 1886 (Colombia, 1886) propició la nueva unidad territorial: el departamento, en detrimento de la provincia original, como una entidad de control político centralizado por el gobierno nacional en Bogotá. Fals Borda (1988) destacó los movimientos políticos y sociales regionales que se manifestaron como la "Resistencia de las provincias", en respuesta del malestar de las etnias y las comunidades, ante la ineficacia de la administración nacional-departamental y que se integrarían a la Asamblea Nacional Constituyente de 1990 y la COT creada para tal fin. La Región-Provincia como prioridad étnico-territorial, fue presentada en el proyecto de ley de la LOOT (20 años antes de su publicación final) y proponía la división del país en ocho regiones, 107 provincias y 50 Entidades Territoriales Indígenas (ETIS). Las regiones eran las siguientes:

- Caribe (Guajira, Bolívar, Cesar, Atlántico, Magdalena, Sucre, Córdoba y San Andrés).

- Pacífico Norte (Antioquia, Risaralda, Caldas, Quindío y Chocó).

- Pacífico Sur (Valle, Cauca y Nariño).

- Andina Norte (Norte de Santander y Santander).

- Andina Sur (Tolima y Huila).

- Central (Bogotá, D. C., Cundinamarca, Meta, Casanare).

- Orinoquia (Arauca, Vichada, Guainía).

- Amazonia (Caquetá, Putumayo, Guaviare, Vaupés y Amazonas) (Moncayo, 2004, p. 181).

Ante el avance de la política municipalista del Estado, Fals Borda insistió en que la descentralización administrativa fiscal debía trascender las unidades municipales hacia el desarrollo de conjuntos supradepartamentales. La noción de la provincia trata del territorio como el ámbito donde se expresan las manifestaciones culturales de las comunidades, en las que las relaciones cotidiano-socioculturales posibilitan la construcción de la región y reivindican la autonomía local. Se plantea el reconocimiento de un ordenamiento territorial conformado por "unidades flexibles" o "provincias o intendencias autónomas" (Fals Borda 1988, p. 11, 83).

Fals Borda (1991) incorpora la flexibilidad como regla general de orientación política, económica y social de naturaleza participativa para facilitar la conformación de esquemas organizativos territoriales, bajo principios de equidad, como la compensación territorial de las diferencias económicas, sociales o de 
infraestructura en el marco de un mejor reparto de condiciones. Asimismo, el concepto de autonomía como atributo de las provincias, consiste en que éstas se constituyen por asociaciones de municipios o territorios vinculados por razones históricas, sociales, culturales, económicas o ecológicas que deberán satisfacer plenamente la participación política, social y económica de los habitantes de los municipios o territorios que las constituyen (Fals Borda, 1991).

La propuesta de Fals Borda se dirige a la transformación del Estado-nación al Estado Unitario, a partir de la base de la autonomía como política socio espacial del territorio. La autonomía territorial exige su administración propia, es decir modifica su Estado (Borja, 1996). Según Lechner (1997), la autonomía depende de la articulación de los espacios de sociedad moderna e implica la diferenciación de campos (economía, derecho, etc.) debidamente acotados y autónomos, volviendo problemática la "unidad" de la sociedad bajo campos que ya no operan desde el vértice jerárquico de un orden piramidal. En este sentido, Trujillo (2007) identifica que la crisis del Estado-Nación vertical concebido "desde arriba", se enfrenta a la descentralización de una sociedad pluralista y a los desafíos ante la idea tradicional de soberanía e identidad nacional, promovidos por las identidades singulares de las subculturas regionales y su diversidad étnicacultural, la productividad y la competitividad, de la mayor exigencia del bienestar social y de infraestructura, así como del desafío ambiental. Basado en La Era de la Información de Castells de 1999, Trujillo (2007), presenta que la reforma del Estado-nación debe darse sobre tres tendencias: la legitimación de las democracias locales; la mayor apropiación de los medios digitales para la participación política; y el desarrollo de políticas simbólicas o de movilizaciones humanitarias o ambientales, que exacerban la capacidad política de una nueva ciudadanía que responde a problemas globales y locales de forma simultánea. 


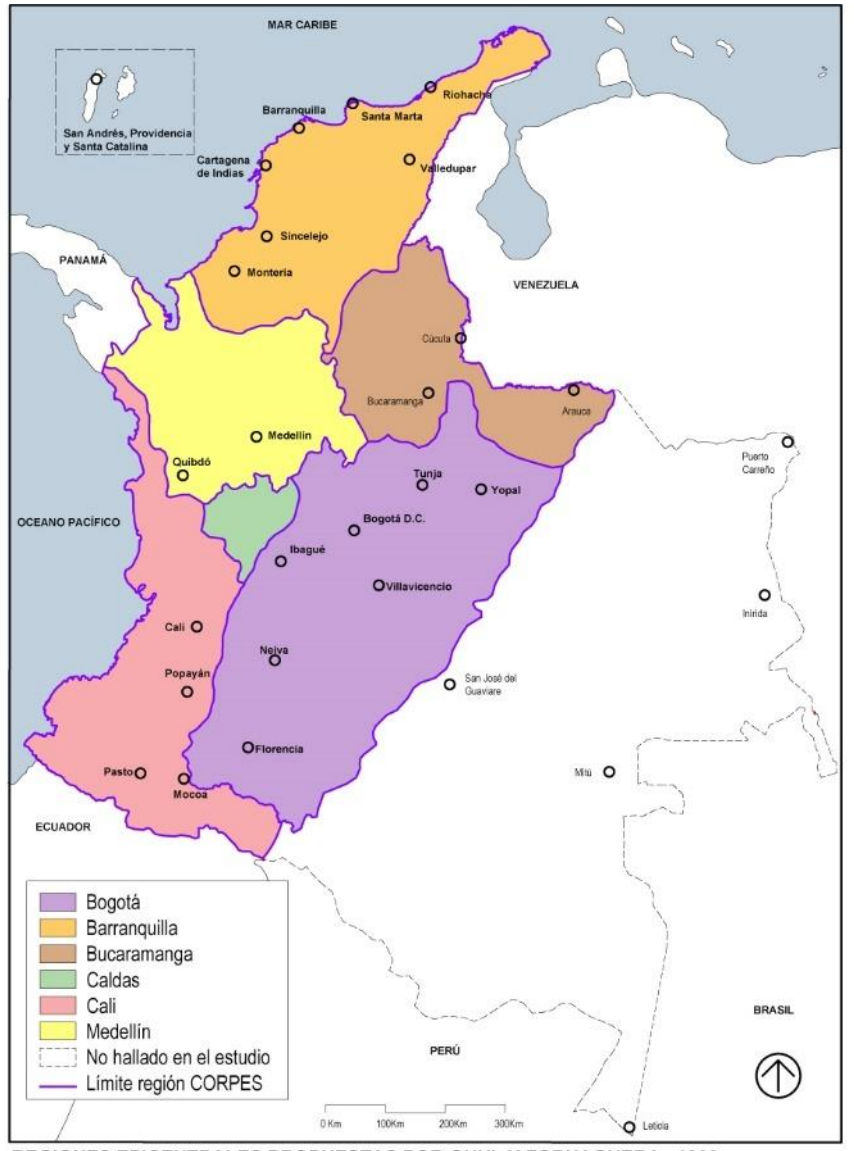

REGIONES EPICENTRALES PROPUESTAS POR GUHL Y FORNAGUERA. 1969.

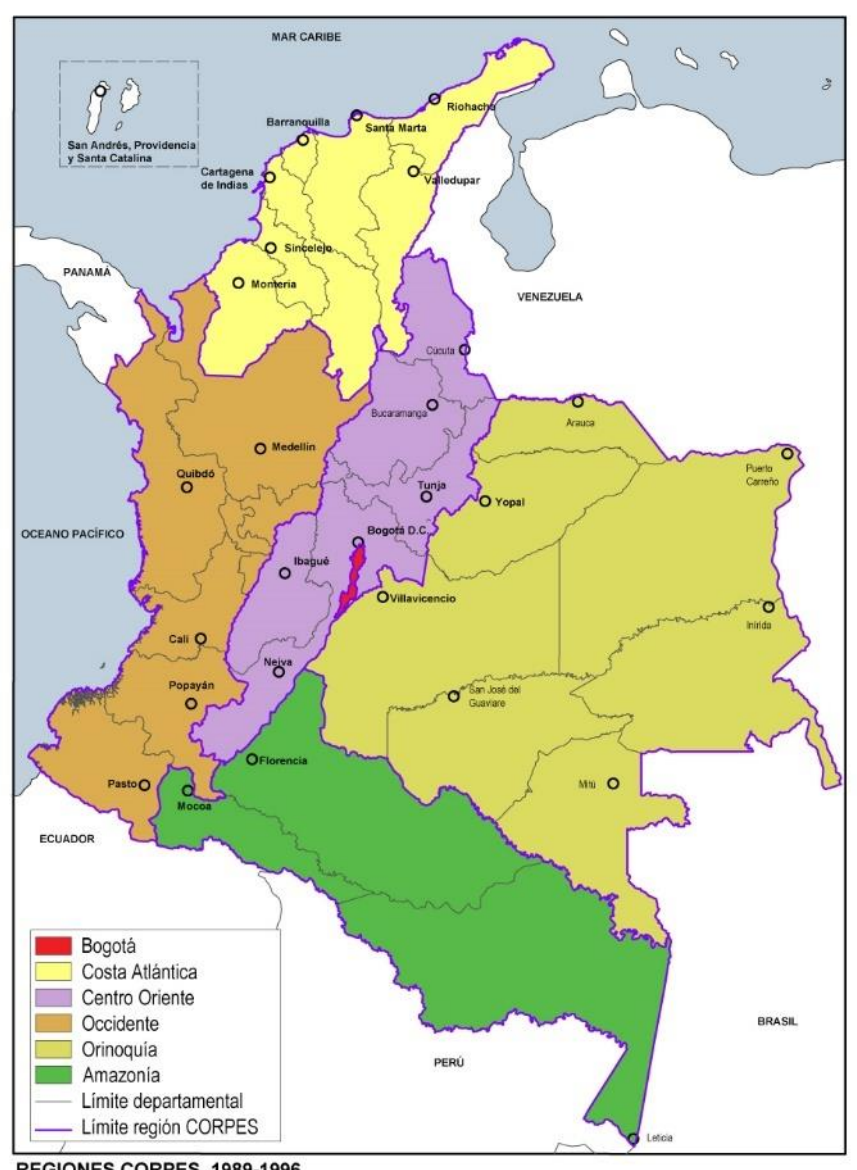

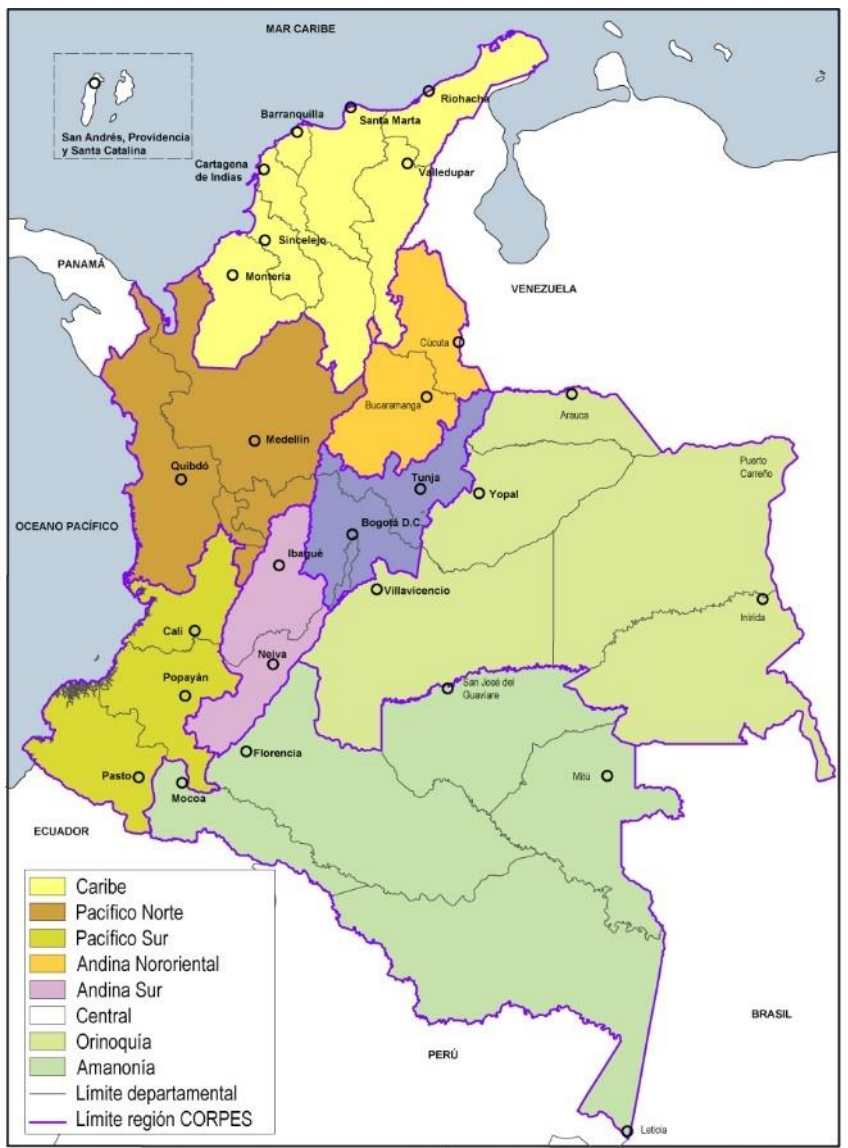

REGIONES ADMINISTRATIVAS Y DE PLANEACIÓN PROPUESTAS POR FALS BORDA. 1987.

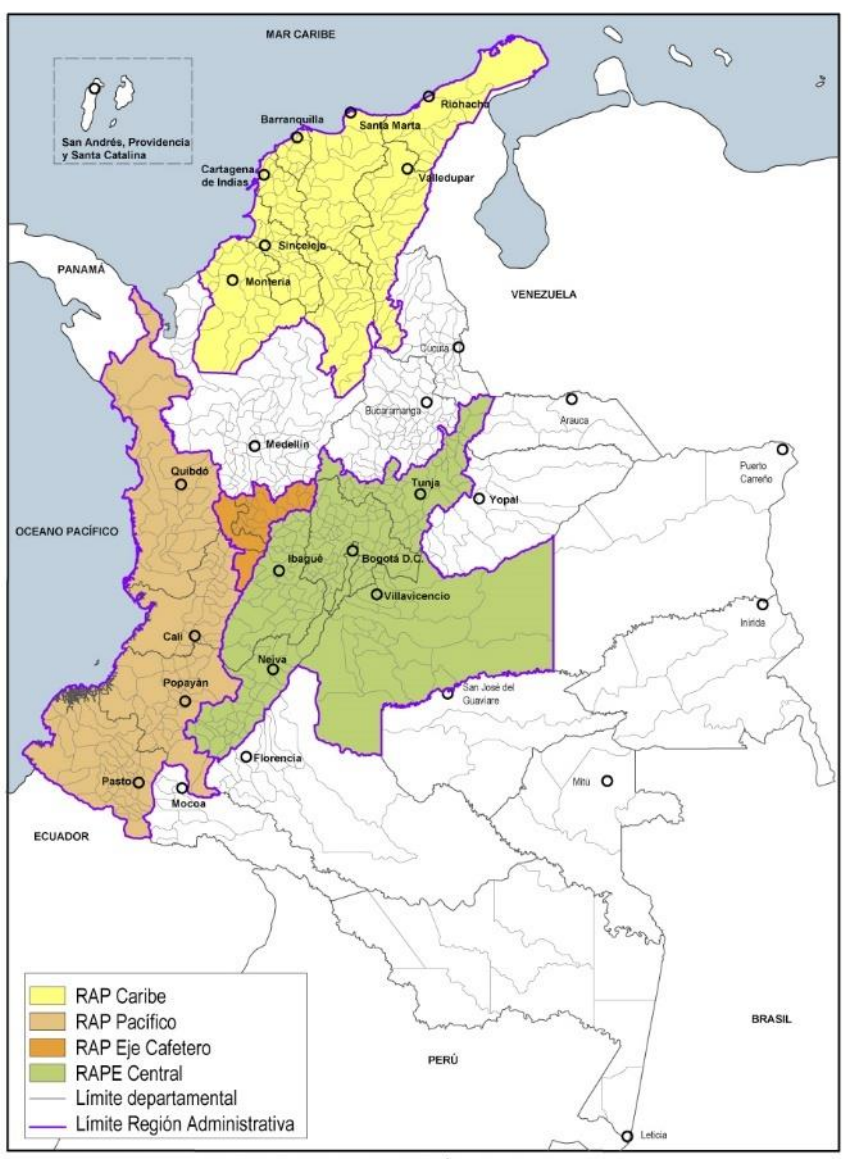

REGIONES ADMINISTRATIVAS Y DE PLANEACIÓN. 2013

Figura 1 - Evolución de la regionalización en Colombia: 1969, 1987, 1989-1996, 2013. Fuente: Editado por los autores a partir de (Sarmiento, 1998; Banco de la República, 2002, p. 10-11; Gaviria \& Aristizábal, 2020, p. 5). 


\section{El Marco Legal}

El marco legal colombiano para la regionalización moderna se originó en la Constitución Política de 1991, que definió aspectos como: a) Descentralización y desconcentración administrativa; b) El reconocimiento de los municipios, departamentos y distritos como entidades territoriales; c) El reconocimiento de la diversidad etnocultural del territorio (Congreso de la República de Colombia, 1991).

La LOOT dictó las normas orgánicas para la organización político-administrativa del territorio, enfocadas a definir el marco institucional e instrumentos para el desarrollo territorial y las competencias en materia de ordenamiento territorial entre la Nación, las entidades territoriales y las áreas metropolitanas. Para ello, estableció principios rectores tales como soberanía y unidad nacional, autonomía, descentralización, integración, regionalización, sostenibilidad, participación, multietnicidad, solidaridad, equidad territorial-social, equilibrio territorial, y buen gobierno.

La LOOT fundamenta la factibilidad de la asociatividad supramunicipal y supra departamental; la política general de ordenamiento; la localización de grandes proyectos de infraestructura; los lineamientos del proceso de urbanización, del sistema de ciudades y la distribución equitativa de los servicios públicos;

y la a conservación y protección de áreas de importancia histórica y cultural. En este marco, las RAP fueron concebidas como entidades conformadas por dos o más entidades territoriales con continuidad geográfica, cuyo financiamiento se logrará por "fondos de compensación, de desarrollo, ciencia y tecnología; regalías directas, contratos plan, y proyectos privilegiados por su componente supramunicipal” (Salazar, 2012, p. 38).

El artículo 306 de la Constitución política de Colombia especifica las RAP: integradas por dos o más departamentos y contarán "[...] con personería jurídica, autonomía y patrimonio propio (Congreso de la República de Colombia, 1991). Su objeto principal será el desarrollo económico y social del respectivo territorio". El artículo 307 plantea además el paso de las RAP a la RET, "lo cual les brinda un grado de autonomía mucho más amplio a aquellas que hayan funcionado por lo menos cinco años" (Gaviria \& Aristizábal, 2020, p. 4).

Los Consejos Regionales de Política Económica y Social (CORPES) creados como una iniciativa para la planificación del desarrollo económico y social, constituyen un antecedente inmediato de las RAP. Pero es el marco institucional de las RAP como esquemas asociativos de entidades territoriales, que según el DNP surgen como instrumentos de articulación y desarrollo territorial para abordar problemas y temáticas que, por su naturaleza y dimensión, no pueden ser atendidas en forma efectiva de manera individual (DNP, 2013).

Hasta el momento, en Colombia se han conformado las RAP Caribe, Pacifico, RAP-E Región Central y la RAP Eje Cafetero, (Figura 1). La primera de ellas, la Región Central, integrada por los departamentos de Boyacá, Cundinamarca, Meta, Tolima y Bogotá, acogen el 29\% de la población del país. La RAP Eje Cafetero integró los departamentos de Caldas, Quindío y Risaralda (Gaviria \& Aristizábal, 2020).

Adicionalmente, otros instrumentos legales como la Ley 1551 de 2012 (Congreso de la República de Colombia, 2012), dictaron normas para modernizar la organización y el funcionamiento de los municipios; la categorización de los distritos y municipios, y la diversificación de competencias. Los documentos del Consejo Nacional de Planeación Económica y Social (CONPES) 3819 de 2014 (DNP, 2014a) aportaron los instrumentos de política nacional para consolidar el sistema de ciudades en Colombia; y por el cual la Nación tiene la competencia de definir los lineamientos del proceso de urbanización y el Sistema de Ciudades. La Ley 1450 de 2011 o Plan Nacional de Desarrollo (PND 2010-2014) (Congreso de la República de Colombia, 2011), indicó la importancia de formular una política de largo plazo para consolidar el Sistema de Ciudades que aproveche de mejor manera los beneficios de la urbanización y de la aglomeración, considerando una mayor integración regional. 


\section{El Marco Metodológico}

En lo que va del siglo XXI, las RAP son la respuesta o la expresión reciente a los procesos de asociatividad en Colombia; por lo tanto, este trabajo busca la interpretación de su origen y validez bajo la pregunta ¿de qué manera han pervivido los conceptos de la región etnocultural de Fals Borda? (Fals Borda, 1988, 2003). Resulta vital desde la ciencia geográfica (humana y cultural), indagar los orígenes etnoculturales de las formas de ordenamiento y de las políticas que han influido espacialmente en el territorio colombiano. Para comprender el ordenamiento actual del territorio, debe darse cuenta de un proceso de interpretación sobre cómo se ha transformado conceptualmente la organización de las regiones. A partir de un enfoque crítico, el desarrollo teórico-conceptual de los orígenes de la regionalización en Colombia rescata los trabajos seminales de Fornaguera \& Guhl (1969) y Fals Borda $(1988,1996,1998,2000$, 2003). (2000)

Fornaguera \& Guhl (1969), desarrollaron la hipótesis acerca de la distribución espacial y temporal del crecimiento demográfico como un indicador del desarrollo diferencial de un área determinada en un período específico, y que las áreas de alto crecimiento demográfico debían coincidir con focos de desarrollo (Ibarra, 2009, p. 11-16). “Concibieron la regionalización un instrumento indispensable para la formulación de políticas de desarrollo, tanto en la ejecución de obras de infraestructura básica, como para la administración pública, la prestación de servicios públicos, o la modificación de situaciones creadas en el proceso de desarrollo histórico" (Rueda \& Ramírez, 2014, p. 14-46), a partir del estudio de los movimientos migratorios en dos niveles significativos: "el comarcal y el de la jerarquización urbana. El primero habría de ser después objeto de profundización en los ámbitos históricos y políticos por parte del sociólogo Orlando Fals Borda, pero en el trabajo de Fornaguera \& Guhl resultaba promisorio al evidenciar el desarrollo desigual del país, traducido en los saldos migratorios, los cuales expresan la atracción o el abandono de estos espacios" (Fajardo, 2011, p. 41).

La regionalización de Fornaguera \& Guhl consideró obsoleta la decisión político-administrativa del país, que podría ser "reemplazada" por las 6 grandes regiones principales (Bogotá, Medellín, Cali, Barranquilla, Bucaramanga y Manizales/Pereira); al interior de cada una se definieron comarcas (73 en total), cada una con un epicentro" (Salazar, 2012, p. 13). El reto de las provincias en la visión territorial supramunicipal o suprarregional de las asociaciones entre municipios, y el rol de las áreas metropolitanas, los distritos y las regiones metropolitanas, representaría una evolución de los intentos de las formas previas de las regiones-plan, la regionalización nodal y los CORPES (Fals Borda, 1991). Fals Borda, reconociendo a Fornaguera \& Guhl, "planteó entonces una región específica, la de la Depresión Momposina, que había que dotarla de una corporación ecológica, autoridad regional o zona económica, con sede en Mompox, por ser el centro geográfico, cultural e histórico de la Depresión, en la que existían cuatro provincias: Mompox; El Banco; Magangué, y San Marcos (Panzenú)" (Rueda \& Ramírez, 2014, p. 51) y adelantó una propuesta de avanzada ante el reto del futuro de las regiones, y la atención a los problemas estructurales del régimen municipal, los servicios domiciliarios, el medio ambiente, las áreas metropolitanas, el gobierno interior y las comunidades (afrocolombianas, raizales, rom) y ETIS (resguardos indígenas).

La Constitución de 1991 consagró como "entidades territoriales" a los municipios, los departamentos y los distritos, y añadió las provincias, las regiones y las ETIS. Asimismo, a partir de la posibilidad de las RAP, Fals Borda (1988), propuso la oportunidad histórica de reconducir una transición hacia la RET. En el marco de esta visión prospectiva, se identifica la pervivencia de los conceptos en el pensamiento de Fals Borda y se pone en valor para el logro de la instrumentación de las RAP y la RET, con el advenimiento de la Ley 1962 de 2019. 


\section{El Territorio como construcción social}

Para Fals Borda (2000), el Estado-nación es el contenedor espacial por tradición. Argumenta que debido a la territorialidad entre naciones concebida bajo líneas imaginarias, las fronteras resultaron condicionadas por la construcción social de estrategias históricamente determinadas por espacios étnicos y simbólicos-políticos de los pueblos asentados con mucha anterioridad al Estado-Nación, fraccionándolos en piezas yuxtapuestas y reducidas a cambios socio-históricos lentos y controlados por el Estado, que sin respeto de la voluntad popular, de la realidad de los procesos locales y/o regionales de naturaleza económica, social o cultural, las sometió a la agresión contra las tierras campesinas y la voracidad del latifundio, la explotación de los recursos naturales y la construcción de vías que rompieron los tejidos comunicacionales de las provincias.

Fals Borda inscribe este proceso en el contexto de la innovación del bioespacio y la tecnorregión. El primero, responde al reconocimiento de los procesos locales y regionales del desarrollo integrado que vinculan las actividades vitales de producción y reproducción de las manifestaciones de la continuidad social y diversidad cultural, es decir, en la articulación de naturaleza-cultura. En esta visión son bioespacios: los resguardos indígenas, las zonas de reserva campesina, los parques naturales, las reservas protectoras, provincias, municipios asociados. El segundo, se define por los vínculos creados por las tecnologías de la información y comunicación, es decir la tecnorregión. Fals Borda (2003) sostiene que, con el auge de la globalización, los procesos de relocalización organizan bioespacios en la escala interna subnacional a partir del ordenamiento territorial social; y la desterritorialización organiza funcionalmente los bioespacios en la escala externa supranacional acorde con la conectividad y la realidad tecnológica y científica en la definición de tecnorregiones (Fals Borda, 2000).

Debe anotarse que a partir de lo anterior, la propuesta de las RAP y una posible RET, deberá articularse con la Misión Sistema de Ciudades (DNP, 2014; Congreso de la República de Colombia, 16 de junio de 2011), como estrategias para orientar y potenciar la actuación y de las entidades nacionales en los territorios y articularla con las políticas de las entidades territoriales, para lograr los fines de desarrollo acordados; y el Conpes 3819 de 2014 (DNP, 2014a), tiene como objetivo fortalecer el Sistema de Ciudades como motor de crecimiento del país, promoviendo la competitividad regional y nacional, el mejoramiento de la calidad de vida de los colombianos y la sostenibilidad ambiental, en un contexto de equidad y posconflicto. 


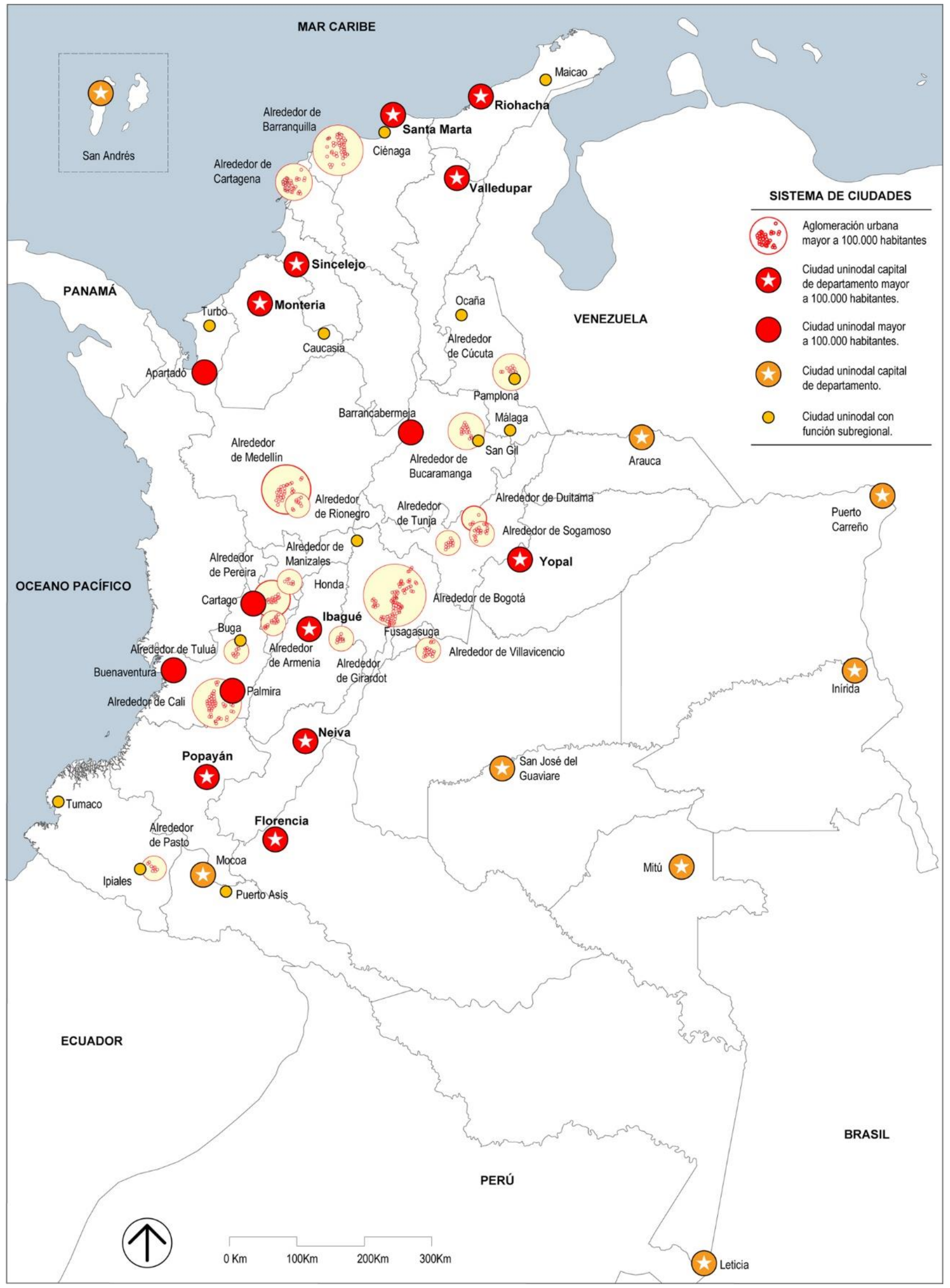

Figura 2 - El Sistema de Ciudades. Fuente: Elaborado por los autores a partir de DNP (2014). 


\section{La prospectiva de la regionalización: de las Comarcas a las RAP y a las RET}

La RAP como figura de planeación suprarregional, permite la función de alianzas estratégicas para el impulso el desarrollo autónomo y autosostenible de las comunidades y la definición de políticas y modos de gestión regional y subregional (DNP, 2013). Esta reciente forma de regionalización considera criterios de conservación de la biodiversidad para el bienestar humano, equidad territorial, responsabilidad territorial, política de interés común inter-jurisdiccional, perspectiva global para el desarrollo y planeación estratégica para la sostenibilidad (DNP, 2013; Terán, 2017). La prospectiva de las RAP se enmarca en la previsión de escenarios de regionalización a futuro, en respuesta al centralismo tradicional y al impacto de las aglomeraciones urbanas. Según Rubiano-Bríñez \& Eligio-Triana (2019), las RAP representan un aprovechamiento "de las ventajas de la asociatividad, pero sin olvidar que el ordenamiento territorial también busca el incremento de la descentralización hacia las regiones y fomenta la autonomía"; y "reconocen las diferencias y potencialidades de cada municipio, generan escenarios de cooperación, no de competencia, ni de divergencia" (Rubiano-Bríñez \& Eligio-Triana, 2019, p. 16).

La interpretación de la visión de Fals Borda dentro de las RAP-RET se cimienta el marco teórico de una genuina visión del territorio desde lo profundo de los enlaces simbólicos de la cultura y la memoria colectiva de los pueblos del Caribe desde sus provincias. También "conviene considerar los conceptos binómicos de Límite y Frontera, Provincia y Región, y Nación y Estado, dentro de la dimensión cultural y socio-lingüística del espacio-historia en Colombia" y la noción de una nueva relación Estado-Región mediante el reordenamiento territorial (Fals Borda, 1988, p. 20).

Guhl (1988) precisó la dimensión de la región antropogeográfica, fundamentada en tres bases: biológica, geográfica-física e histórico-cultural. La región que aloja la visión de Fals Borda se subdivide por espacios naturales (ríos, valles, cordilleras), y son orientadores del paisaje cultural (Guhl, 1988, p. 171). Las comarcas actúan como unidades o ecotopos que responden a los valores locales socioambientales de la comunidad y la biodiversidad del paisaje. En estas unidades se permite la "articulación entre lo local y lo global, indispensables para entender estas realidades y proceder a transformarlas con eficacia y justicia" (Fals Borda, 1998, pág. 32). Fals Borda, observa los retos de las RAP y la RET como "pivotes y actores del reordenamiento por la paz" y como una base para "la reconstrucción de la gobernabilidad local" (Fals Borda, 1998). Funcionan como unidades culturales menores que caracterizan las unidades de paisaje de la subregión; concepto que "se aplica generalmente a la siguiente unidad en sentido descendente, pero los científicos también utilizan términos como comarca, centro, zona, distrito y provincia" (Vance, 1976, p. 161). Dentro de la lógica escalar, cada componente, contiene en su interior mayor homogeneidad que la precedente; y los habitantes que en ella se agrupan tienen características que los identifican "entre sí por costumbres, dialectos y estilos de vida propia: es decir, con la cultura popular que se expresa desde la cocina hasta la música, la danza, la literatura y la vivienda en nichos ecológicos determinados" (Fals Borda, 1988, p. 27-28).

En 1990, gracias al liderazgo de Fals Borda como miembro de la Asamblea General Constituyente que modificó la Constitución Política, se interpuso la gestión de la COT, del nuevo modelo territorial (Estupiñán, 2006; Sarmiento, 1998). Posteriormente en 1997, fue emitida la Ley 388 de Ordenamiento Territorial (Congreso de la República de Colombia, 1997), que obligó a los municipios de Colombia a contar con respectivos Planes de Ordenamiento Territorial (POT). Ésta "omitió admitir planes más amplios para combinar municipios a nivel de asociaciones, áreas metropolitanas o provincias, lo que era y sigue siendo más realista y económico. Todavía hay tiempo para corregir dicha ley y aprender de ella y de las otras mencionadas" (Fals Borda, 1996, p. 28).

Crítico ante esta ley, Fals Borda sugiere insistir en la RAP (El Tiempo, 1998) y las RAP del Caribe como ejemplo (Fals Borda, 1996, p. 28) (Fals Borda, 1996, pág. 28); y que, por su parte, la LOOT, apenas se remite a mencionar las posibilidades de la asociatividad como una opción. En vista de la problemática derivada del crecimiento de las aglomeraciones urbanas en Colombia, sería factible la revisión de la operación de las Áreas Metropolitanas aprovechando las RAP, que deben permitir una planeación del desarrollo de 
infraestructuras y proyectos de desarrollo económico regional; de igual forma con el desarrollo de programas de vivienda de interés social y prioritario; la ejecución de estudios y planes de transporte regional; la construcción de infraestructuras viales y de servicios públicos regionales y la dotación de equipamientos sociales (Salazar, 2012, p. 90).

La realidad de Colombia como país de Regiones, Provincias, Territorios Indígenas y Afrocolombianos se encontrarían en un mismo proyecto histórico de desarrollo económico y social para la Paz, frente al siglo XXI. "La RET es la meta. Las RAP deben ser una etapa corta para llegar a la meta de autonomía y poder regional que es la RET total, es decir, el Estado Región (...) La RET asumiría todas las funciones autonómicas del Artículo 287 de la Carta Constitucional" (Fals Borda, 1998, p. 10). Fals Borda tenía la visión de las RET menos funcionalistas y más activas en su pensamiento de la IAP (Investigación-Acción-Participación) (Bozzano, 2017), como apuesta por la acción de la participación popular; la obtención y ejecución coordinada de recursos; la búsqueda del equilibrio regional; la asunción de funciones centralizadas; el reconocimiento de autonomía. En suma, Fals Borda propende por una República regional, en la que:

La Región y la Provincia aparecen aquí como pivotes primordiales para construir el Estado nuevo desde aquellos diversos ángulos. Reconocerlas es parte de la búsqueda para resolver conflictos locales que hoy desbordan a municipios y departamentos individuales como unidades que son incapaces de hacer frente a los problemas contemporáneos. No existe proyecto de desarrollo económico bien concebido que no busque la combinación espacial de aquellas entidades: lo macro es siempre provincial y regional (Fals Borda, 1998, p. 12).

Treinta y un años después del proyecto de Fals Borda (1991), la Ley 1962 de 2019 (Congreso de la República de Colombia, 2019), reglamentó las RAP y los principios para la conformación del modelo de RET:

a) Fomentar el fortalecimiento de las capacidades institucionales de los entes territoriales que la conforman.

b) Fomentar la identidad cultural regional, basada en los principios de respeto a la diversidad y la diferencia, no discriminación y la convivencia pacífica.

c) Diseñar e impulsar la ejecución de planes, programas y proyectos de interés mutuo y que conduzcan al desarrollo integral sostenible.

d) Promover la incorporación del enfoque regional en los POT y en los diferentes instrumentos de planificación.

e) Participar en los procesos de ordenamiento y planificación de los recursos naturales del componente ecológico y ambiental de la región.

i) Gestionar recursos de cofinanciación de los diferentes niveles de gobierno, de cooperación internacional y promover alianzas público-privadas para el desarrollo de proyectos estratégicos.

j) Promover la constitución y fortalecimiento de las redes de ciudades como dinamizadoras del desarrollo regional, con visión incluyente hacia los diferentes grupos sociales y etnias que la habitan. k) Impulsar la investigación y la producción de conocimiento a nivel regional (Congreso de la República de Colombia, 2019, p. 1-2).

La RET, por su parte, tendrá atribuciones orientadas al desarrollo económico y social del respectivo territorio, bajo los principios de convivencia pacífica, sostenibilidad, inclusión, equidad y cierre de brechas intra e interregionales y urbano-rurales. Cada RET deberá contar con un Estatuto Especial que se adoptará los principios adicionales de: 1) Paz integral esencial como valor fundante del Estado Social de Derecho; 2) Reconocimiento de la pluralidad y de la diversidad territorial; 3) Enfoque de derechos y de género; 4). Respeto a la diversidad étnica, cultural y de orientación sexual, en reconocimiento al derecho a la no discriminación de las personas, las minorías y los grupos poblacionales; 5). Promoción de la Regionalización, impulsando la competitividad en el marco de la especialización inteligente (Congreso de la República de Colombia, 2019, p. 4-5). 


\section{Las RAP y las estrategias de integración regional}

Según el informe "Una nueva geografía económica" (Banco Mundial, 2009), las políticas sobre integración regional se han construido sobre tres ejes centrales: a) la urbanización o políticas enfocadas a mejorar los estándares de urbanismo; b) el desarrollo territorial, acorde a las políticas internas para promover la integración regional a nivel local; c) la integración internacional y funcional entre las naciones teniendo en cuenta que las regiones tienden a ser más especializadas y competitivas en sus partes, pero más desequilibradas en su conjunto.

La consolidación de un proceso de regionalización en Colombia (RAP-RET), gravita debido a los procesos de metropolización bajo efectos de subordinación y dependencia (Alfonso, 2014), que han modificado los conceptos de "interacción" y "jurisdicción concernida en el fenómeno metropolitano", inter- núcleos metropolitanos o inter-municipio metropolizados o inter-nucleos y municipios metropolizados (Alfonso, 2014, p. 125) . Asimismo, esto depende de la articulación con las potencialidades culturales del territorio, en términos de las oportunidades integradoras de los paisajes culturales agroproductivos; y requiere de la armonización de los procesos urbanos con el ordenamiento rural del territorio; así como incluirse en la transición hacia los territorios inteligentes/smart cities. Lo que Guhl define como el dominio de un hábitat por parte de los grupos sociales, "convirtiendo a éste en un área cultural, que es la consecuencia de un proceso de desarrollo, basado en el engranaje de dos grupos de fuerzas. La una viene del paisaje cultural, y la otra representa al hombre en su actividad de modificador cultural del paisaje natural. En este proceso de capacidad de evaluación (de los recursos naturales) están fundamentados los motivos para la modificación del paisaje natural en un área cultural. Constituye este proceso la lucha del hombre con su medio geográfico, y a la vez encierra todo el problema de la geografía cultural" (Fals Borda, 1988, p. 166-167).

Una estrategia de integración dentro de la RAP debe dar cuenta de las transformaciones recientes, de corte transversal y que propicia la necesidad de la visión prospectiva más amplia. Los "territorios inteligentes" significan un cambio trascendental, particularmente para la eficiencia de la administración de los servicios públicos y privados, y su apertura como canal de comunicación entre los gobiernos locales, las administraciones y los usuarios de las ciudades y el territorio. Debe pensarse en cómo iniciar el proceso de inserción del cambio tecnológico de las TIC en la vida diaria de los habitantes de las ciudades y su región, de acuerdo con sus condiciones actuales y futuras. Por tal motivo, la accesibilidad al territorio inteligente permite considerar un amplio espectro de posibilidades en la gestión de los servicios públicos del siglo XXI, en función de la tendencia actual de la gobernabilidad participativa, toda vez que signifique un mejoramiento en la calidad de los servicios y la democratización de la información generada por los indicadores de gestión (Vergara \& De las Rivas, 2016; 2004; Gaviria \& Aristizábal, 2020).

\section{Conclusiones}

En consecuencia con el orden legal estructural (Constitución de 1991), la reciente Ley 1969 de 2019 (Congreso de la República de Colombia, 2019), cumple parcialmente la visión de Fals Borda. Aunque permite contar hoy con los elementos para revisar la organización y el funcionamiento espacial del sistema urbanoregional del territorio colombiano, con base en el reto que significa la puesta en marcha de las RAP-RET y el reconocimiento de la diversidad etnocultural (socioantropogeográfica) del territorio. La autonomía que reclaman las regiones no puede ser exclusivamente administrativa, como lo han venido proponiendo los esquemas centralistas tradicionales, sino autonomistas (Ibarra, 2009).

Con la Ley 1962 de 2019, se establecen las condiciones y el procedimiento para la conversión de departamentos en RET, así como reglamentar su funcionamiento y regular las relaciones entre éstas y las otras entidades territoriales existentes, pero se carece de la fortaleza del carácter multidiverso y antropogeográfico con una visión prospectiva (CEPAL, 2013). La expresión espacial de las relaciones múltiples, diversas y complejas, presentes en el territorio colombiano de los últimos treinta años, puede dar 
cuenta de la transformación del país y la apuesta por reconocer sus adelantos, pero también sus carencias. Las regiones locales y la organización de ciudades locales-globales han entrado productivamente en la competitividad de los mercados, con un efecto territorial-espacial sobre la sostenibilidad, la calidad de vida y el acceso a las tecnologías de la información y la comunicación; cuando padecen aún del contraste con la pobreza y la falta de infraestructura básica. Lo cual urge a activar la operatividad de las RAP para reducir estas brechas.

Las RAP representarán entonces un gran reto que puedan enfrentar conceptos de mayor innovación como la "inteligencia territorial" y "la justicia territorial"; además del fortalecimiento de "(a) territorialidades, temporalidades y organizaciones, (b) crecimiento productivo y económico en el orden local, y (c) procesos de conocimiento" (Botero \& Piza, 2017 apud Bozzano, 2017, p. 77, Espinosa, 2001, Estupiñán, 2006). La resolución de las asimetrías intraterritoriales, frente a la extensión de las fortalezas y oportunidades del centro hacia la periferia constituye uno de los principales retos del proceso de integración regional (UNCRD-Secretaria de Planeación Distrital, 2014). La armonización de los procesos urbanos con el ordenamiento rural del territorio tiene un potencial como reto en el espacio territorial de las RAP, en el contexto cultural de los paisajes culturales, en el rediseño en función de los territorios inteligentes y las smart human cities (aunque no se ajustan a la tecnorregión súper especializada de Fals Borda), lógicamente operan con base en la accesibilidad masiva al Big Data. Dentro de la "nueva política regional" (De Mattos, 2000) los retos de las regiones se concentran en la atractividad y de innovación en materia del desarrollo del capital humano, aprendizaje, capacidades empresariales, y especializaciones subnacionales (locales-metropolitanas) para una mayor competitividad.

El pensamiento de Fals Borda perdura desde la concepción de las RAP hace 30 años, cuyo reto inicial y final continúa siendo la estrategia política y de gobernabilidad para favorecer la integración regional que reduzca los desequilibrios, la ejecución de una política en función del poder territorial histórico de los grupos humanos que habitan y trabajan en las provincias. Este está presente en la premisa de una innovación social-territorial, la necesidad de las voluntades políticas internas y reactivas en un marco de coherencia y consenso sobre la paz territorial. Pero, el cambio periódico de gobiernos departamentales, y la incertidumbre por el recrudecimiento de la violencia de Estado después de la firma de la Paz, en entorno del posconflicto en el contexto de la crisis política, social y económica de Colombia, amenaza las garantías para continuar con un proceso que debe ser ratificado y legitimado con cada gobierno, y que no ponga en riesgo todo lo avanzado.

Finalmente, queda abierta la articulación funcional de las RAP para evolucionar a un Estado RegionalRET como salida a la inercia institucional de los departamentos dentro de las RAP. Los departamentos continuarán sólo como parte de la maquinaria o engranajes de la planificación económica y social, pero el Consejo Administrativo de la RAP empezará a tener más fuerza por el poder de convocatoria para la ejecución de los proyectos como regiones autónomas, con asignaciones presupuestales propias. Aunque es muy posible que el statu quo de las bases electorales, clientelistas y judiciales de los poderes caciquistas dentro de los departamentos se mantengan. Este será el debate político-administrativo en el que empezarán a competir los departamentos frente a la eficiencia que se vislumbra en el inicio de gestiones de las RAP en Colombia. Sorprende que, en la gesta de Fals Borda, no se detecta una visión sobre el desarrollo sostenible, incluso en sus aportaciones más recientes, con la cual puede afirmarse que hay un consenso, y por el cual las comunidades locales están más interesadas y representadas por sus organizaciones sociales propias. Debe destacarse en este enfoque, la línea de base provista por la ecorregión en la RAP Eje Cafetero, por ejemplo. Pero que, en sincronía con la construcción social desde las células sociales, el pensamiento de Fals Borda y la Investigación-Participación-Acción, inspiraron los procesos académicos y sociales con los colectivos ambientales para la apropiación y el desarrollo de conocimiento de la Ecorregión (Gaviria \& Aristizábal, 2020). 


\section{Referencias}

Alfonso, O. A. (2014). Los Desequilibrios territoriales en Colombia. Estudio sobre el sistema de ciudades y el polimetropolitanismo. Bogotá: Universidad Externado de Colombia.

Banco de la República. (2002). Las regiones económicas de Colombia: Un análisis de clusters. En Barón, J. D. Documentos de trabajo sobre economía nacional (Vol. 23). Cartagena de Indias: Centro de estudios económicos regionales.

Banco Mundial. (2009). Informe de Desarrollo Mundial. Nueva Geografía Económica. Washington: Banco Mundial.

Belil, M., \& Clos, I. (1983). Notes a l'entorn del pensament de Carl O. Sauer. Documents d'Anàlisi Geogràfica, (2), 177-188. Recuperado el 9 de Agosto de 2021, de https://dialnet.unirioja.es/servlet/articulo?codigo=237685

Boisier, S. (2006). Algunas reflexiones para aproximarse al concepto de ciudad-región. Estudios Sociales, 15(28), $164-190$. Recuperado el 9 de Agosto de 2021, de https://dialnet.unirioja.es/servlet/articulo?codigo=2099855

Borja, M. (1996). Estado, Sociedad y Ordenamiento Territorial en Colombia. Bogotá: IEPRI.

Bozzano, H. (2017). Territorios posibles e inteligencia territorial: una fórmula entre la gente, la ciencia y las políticas públicas. Casos en Argentina y Colombia. Análisis Geográficos, 54, 26-85. Recuperado el 9 de Agosto de 2021, de https://ciaf.igac.gov.co/sites/ciaf.igac.gov.co/files/revista_analisis_geograficos_n54_compressed.pdf

Castells, M. (1995). La Ciudad Informacional. Tecnologías de la información, estructuración económica y el proceso urbanoregional. Madrid: Alianza.

CEPAL. (2013). Guía: Análisis del Sistema Urbano Regional para el Ordenamiento Territorial. Santiago de Chile: CEPALNaciones Unidas.

Colombia, D. A.-G. (1886). www.funcionpublica.gov.co. Recuperado el 9 de Agosto de 2021, de https://www.funcionpublica.gov.co/eva/gestornormativo/norma.php?i=7153

Colombia, D. A.-G. (s.f.). Funcionpublica.gov.co. Recuperado el 9 de Agosto de 2021, de https://www.funcionpublica.gov.co/eva/gestornormativo/norma.php?i=7153

Congreso de la República de Colombia. (6 de Julio de 1991). Constitución Política de Colombia de 1991. Diario Oficial de Colombia. Bogotá, D.E.

Congreso de la República de Colombia. (24 de Julio de 1997). Ley 388 de 1997. Bogotá: Diario Oficial No. 43.091.

Congreso de la República de Colombia. (16 de Junio de 2011). Ley 1450. Por la cual se expide el Plan Nacional de Desarrollo 2010-2014.

Congreso de la República de Colombia. (28 de Junio de 2011). Ley 1454 del 2011. Reglamentada por el Decreto Nacional 3680 de 2011. Diario Oficial de Colombia.

Congreso de la República de Colombia. (6 de Julio de 2012). Ley 1551 de 2012.

Congreso de la República de Colombia. (28 de Junio de 2019). Ley 1962 de 2019. Bogotá, Colombia: Diario Oficial de Colombia.

De Mattos, C. A. (2000). Nuevas teorías del crecimiento económico: lectura desde la perspectiva de los territorios de la periferia. Territorios, (3), 43-68. Territorios, III, 43-68. Recuperado el 9 de Agosto de 2021, de https://revistas.urosario.edu.co/index.php/territorios/article/view/5618

DNP. (2013). Definición legal y funcional de los esquemas asociativos de entidades territoriales en Colombia. Bogotá: DNP.

DNP. (2014). Misión Sistema de Ciudades: Una política nacional para el Sistema de Ciudades colombiano con visión a largo plazo. Bogotá: Departamento Nacional de Planeación.

DNP. (21 de Octubre de 2014a). Documento CONPES 3819. Política Nacional para consolidar el Sistema de Ciudades en Colombia. Bogotá: Consejo Nacional de Política Económica y Social.

El Tiempo. (25 de Julio de 1998). Fals sugiere insistir en la RAP. Diario El Tiempo. Recuperado el 9 de Agosto de 2021, de https://www.eltiempo.com/archivo/documento/MAM-818275

Espinosa, M. (Junio de 2001). Región y ordenamiento territorial: la encrucijada del proyecto territorial nacional. Sociedad Geográfica de Colombia, 45(133). Recuperado el 9 de Agosto de 2021, de

https://www.sogeocol.edu.co/documentos/region_y_o_t.pdf 
Estupiñán, L. (Julio - diciembre de 2006). El modelo territorial colombiano: crisis y perspectivas. Diálogos de saberes, (25), 91-108. Recuperado el 9 de Agosto de 2021, de https://dialnet.unirioja.es/servlet/articulo?codigo=2693566

Fajardo, D. (2011). Ordenación del territorio y reforma agraria en el pensamiento de Ernesto Guhl. Boletín Cultural y Bibliográfico, 46(81), 35-49. Recuperado el 9 de Agosto de 2021, de https://publicaciones.banrepcultural.org/index.php/boletin_cultural/article/view/17

Fals Borda, O. (1988). La insurgencia de las provincias. Hacia un nuevo ordenamiento territorial para Colombia. Bogotá: Siglo XXI Editores.

Fals Borda, O. (14 de Abril de 1991). Provincias y Asociaciones (rurales)de Municipios. Foro, (14), 51-61.

Fals Borda, 0. (1996). Región e Historia. Elementos sobre ordenamiento y equilibrio regional en Colombia. Bogotá: Tercer Mundo-IEPRI Universidad Nacional de Colombia. Recuperado el 20 de Marzo de 2020, de https://revistas.unal.edu.co/index.php/anpol/article/view/74517

Fals Borda, O. (1998). Guía Práctica del Ordenamiento Territorial en Colombia: contribución para la solución de conflictos. (I. d. Internacionales, Ed.) Bogotá: (IEPRI)- Universidad Nacional de Colombia. Obtenido de http://www.mamacoca.org/e_book_Compendio_rural/Orlando_Fals_Borda_guia_practica_ordenamiento.html

Fals Borda, 0. (2000a). Acción y espacio: autonomías en la nueva república. Bogotá: TM Editores.

Fals Borda, O. (Marzo de 2000b). El territorio como construcción social. Foro, (38), 45-51.

Fals Borda, O. (Diciembre de 2003). Hacia la II Gran Colombia: función integradora de cuencas y naciones indígenas binacionales. Foro, (49), 90-96.

Fornaguera, M., \& Guhl, E. (1969). Ordenación del territorio en base del epicentrismo regional. Bogotá: Universidad Nacional de Colombia. Recuperado el 9 de Agosto de 2021, de http://www.cid.unal.edu.co/cidactual/index.php?option=com_publicaciones\&op=view\&Itemid=417\&adressid=114

Fujita, M. (2005). Spatial Economics. Cheltenham: Edward Elgar Publishing.

Fujita, M., \& Krugman, P. (2004). La nueva geografía económica: pasado, presente y futuro. Investigaciones Regionales, (4), 177-206. Recuperado el 9 de Agosto de 2021, de https://www.redalyc.org/pdf/289/28900409.pdf

Fujita, M., Krugman, P., \& Venables, A. (2000). Economía Espacial: las ciudades, las regiones y el comercio internacional. Barcelona: Ariel.

Garcia, M. ( 1985). Teoría y método en la geografía humana anglosajona. Barcelona: Ariel.

Gaviria, M. A., \& Aristizábal, A. F. (2020). Caracterización funcional de la RAP Eje Cafetero. Urbe. Revista Brasileira de Gestão Urbana, 12, e20200052. doi https://doi.org/10.1590/2175-3369.012.e20200052

Guhl, E. (1988). La geografía y el ordenamiento territorial. En Fals, O. La Insurgencia de las Provincias. Hacia un nuevo ordenamiento territorial para Colombia (págs. 143-236). Bogotá: Universidad Nacional de Colombia - Siglo XXI editores.

Ibarra, J. (Abril - Septiembre de 2009). Enfoques regionales y factores políticos sobre el ordenamiento territorial en Colombia. Justicia Juris, 6 (11), 11-16. Recuperado el 9 de Agosto de 2021, de http://hdl.handle.net/11619/1019

Instituto Geográfico Agustín Codazzi. (1986). Estructura urbano regional colombiana (Vol. 17). Bogotá: IGAC.

Instituto Geográfico Agustín Codazzi. (2011). Organización y configuración urbano-regional. En IGAC, Geografía de Colombia (págs. 227-277). Bogotá: IGAC-Imprenta Nacional de Colombia.

Jackson, P. (1989). Maps of meaning. Londres: Routledge.

Lechner, N. (diciembre de 1997). Cultura Política y Gobernabilidad Democrática. Foro, (33), 5-12.

Lindon, A., \& Hiernaux, D. (2006). Tratado de geografía humana. Barcelona: Anthropos Editorial.

Luna García, A. (1999). ¿Qué hay de nuevo en la nueva geografía cultural? Documents d'Analisi Geogràfica, (34), 69-80. Recuperado el 9 de Agosto de 2021, de https://ddd.uab.cat/pub/dag/02121573n34/02121573n34p69.pdf

Molina, H., \& Moreno, P. (2001). Aportes para una nueva regionalización del territorio colombiano. En O. Alfonso, Ciudad y región en Colombia: Nueve Ensayos de análisis socioeconómico y espacial (págs. 579-385). Bogotá: Universidad Externado de Colombia. 
Moncayo, E. (2004). Nuevos enfoque del desarrollo territorial: Colombia en una perspectiva latinoamericana. Bogotá: Universidad Nacional de Colombia. Red de Estudios de Espacio y Territorio, UNPD, CEPAL.

ONU-HÁBITAT. (2012). Estado de las ciudades de América Latina y el Caribe 2012. Rumbo a una nueva transición urbana. ONU-HÁBITAT.

Rubiano-Bríñez, M., \& Eligio-Triana, C. (Septiembre de 2019). Regiones administrativas y de planificación: análisis comparativo de las primacías urbanas en la RAPE Región Central y RAP Pacífico. Urbe. Revista Brasileira de Gestão Urbana, 11, 1-20. doi:10.1590/2175-3369.011.e20180107

Rueda, J., \& Ramírez, R. (Enero - junio de 2014). Historiografía de la regionalización en Colombia: una mirada institucional e interdisciplinar. Historelo, 6(11), 13-67. doi https://doi.org/10.15446/historelo.v6n11.42005

Salazar, J. (2012). Fortalecimiento del sistema de ciudades. Instrumentos de planificación. Bogotá: DNP.

Sánchez, F. J., \& Nuñez, J. (2000). Geography and economic development: a municipal approach for Colombia. Bogotá: CEDES. Universidad de los Andes. Recuperado el 9 de Agosto de 2021, de http://hdl.handle.net/1992/8757

Santos, M. (2000). La naturaleza del espacio. Técnica y tiempo. Razón y emoción. Barcelona: Ariel.

Sarmiento, L. (1998). Municipios y Regiones de Colombia: Una mirada desde la sociedad civil Bogotá, Colombia. Santafé de Bogotá: Fundación Social Ediciones.

Sassen, S. (Diciembre de 2007). El reposicionamiento de las ciudades y regiones urbanas en una economía global: ampliando las opciones de políticas y gobernanza. Eure, 33(100), 9-34. doi http://dx.doi.org/10.4067/S0250-

71612007000300002

Sauer, C. (1962). Cultural Geography. En Wagner, P. L. \& Mikesell, M. W. Readings in Cultural Geography (págs. 30-34). Chicago: The University of Chicago Press.

Terán, J. M. (Julio de 2017). Rap Pacífico: iniciativa de planificación y gestión conjunta del Pacífico Colombia. Documentos de trabajo del PEAP. Cali: Universidad Icesi.

Trujillo, A. (2007). Democracia y territorio. El ordenamiento territorial entre el derecho y la política. Bogotá: Siglo del Hombre Editores. Academia colombiana de Jurisprudencia.

UNCRD-Secretaria de Planeación Distrital. (2014). Rape Región Central. Territorio para la Paz. Documento Técnico de Soporte (DTS). Bogotá: La Imprenta Editores.

Universidad Nacional de Colombia - UN. (22 de Junio de 2015). Ernesto Guhl, pionero en estudios en geografía. Bogotá D.C.: Agencia de Noticias UN. Unimedios. Recuperado el 9 de Agosto de 2021, de https://agenciadenoticias.unal.edu.co/detalle/article/ernesto-guhl-pionero-en-estudios-en-geografia.html

Valdivia, M., \& Delgadillo, J. (2013). La geografía y la economía en sus vínculos actuales. Una antología comentada del debate contemporáneo. Cuadernos de geografía: Revista colombiana de geografía, 21-37. Recuperado el 9 de Agosto de 2021, de http://biblioteca.clacso.edu.ar/Mexico/crim-unam/20170505052459/pdf_664.pdf

Vance, R. B. (1976). Región. En Sills, D. L. Enciclopedia Internacional de las Ciencias Sociales (Vol. 9). Madrid: Aguilar.

Vergara, A., \& De Las Rivas, J. L. (2004). Territorios inteligentes, territorios sostenibles. Madrid: Fundación Metrópoli. Obtenido de https://issuu.com/fundacionmetropoli/docs/territorios_inteligentes_fundacion_metropoli

Vergara, A., \& De las Rivas, J. L. (2016). La Inteligencia del territorio Supercities. Madrid: Fundación Metrópoli-Findeter. Obtenido de https://issuu.com/fundacionmetropoli/docs/supercities_ed._espa_a

Editor responsável: Rodrigo Firmino

Recibido: 17 dez. 2020

Aprobado: 05 jul. 2021 


\section{Errata}

En el artículo "Orígenes de la planeación regional en Colombia y sus retos ante el territorio del siglo XXI”, con el número de DOI https://doi.org/10.1590/2175-3369.013.e20200419, publicado en urbe. Revista Brasileira de Gestão Urbana, vol. 13, e20200419, en la página 1,

donde lees:

"(b) Universidad del Tolima, Facultad de Humanidades, Artes y Ciencias Sociales, Ibagué, Tolima, Colombia."

leer:

“(b) Universidad del Tolima, Facultad de Tecnologías, Ibagué, Tolima, Colombia." 